JURNAL NUANSA INFORMATIKA

Volume 13 Nomor 2, Juli 2019
p-ISSN : 1858-3911, e-ISSN : 2614-5405

https://journal.uniku.ac.id/index.php/ilkom

\title{
IMPLEMENTASI ALGORITMA FISHER YATES UNTUK PENGACAKAN SOAL PADA APLIKASI MOBILE LEARNING KUIS FIQIH BERBASIS ANDROID
}

\author{
Rio Priantama ${ }^{1}$, Yuda Priandani ${ }^{2}$ \\ Fakultas Ilmu Komputer Universitas Kuningan \\ Jalan Tjut Nyak Dhien No. 36 A Cijoho Kuningan Jawa Barat 45513Telepon (0232) 2875097 \\ Email: rio.priantama@uniku.ac.id, aduy.dayz@gmail.com
}

Proses pembelajaran konvensional yang dilakukan dengan tatap muka, kurang efektif sebagai sumber pembelajaran, karena fokus ketertarikan peserta didik saat ini sudah bergeser pada perangkat gawai mereka sehingga peserta didik kesulitan dalam mengulangi materi pembelajaran. Penelitian ini bertujuan untuk menghasilkan media pembelajaran berbasis mobile learning pada platform android yang digunakan sebagai sumber belajar aplikasi fiqih pada anak didik. Aplikasi mobile learning ini di bangun dengan menerapkan algoritma Fisher Yates Shuffling atau biasa dikenal dengan algoritma Fisher Yates yang saat ini telah banyak digunakan dalam proses pengembangan aplikasi-aplikasi pengacakan. Metode pengacakan ini merupakan metode pengacakan yang optimal dalam pengembangan aplikasi, karena mampu mengacak banyaknya materi tentang ilmu fiqih dan mencegah kecurangan pengguna yang hanya menghafal jawaban tanpa memahami materi ketika soal bersifat tetap atau tidak acak. Aplikasi dibangun menggunakan MySQL sebagai basis data yang dirancang untuk mengelola dan memanipulasi data dengan cepat dan mudah. PHP dan Perl digunakan sebagai bahasa pemrograman script untuk internet dan berkolaborasi pada platform Android. Metode pengembangan sistem yang digunakan adalah RUP (Rational Unified Process) dengan mengumpulkan berbagai best practices yang terdapat dalam industri pengembangan perangkat lunak.

Pengujian sistem dilakukan menggunakan white box dan black box testing menunjukan bahwa algoritma Fisher Yates dapat diterapkan di dalam aplikasi mobile learning kuis fiqih sebagai pengacak soal . Hasil pengujian User Acceptance Model (UAT) menunjukan bahwa aplikasi mobile learning ini dapat membantu proses pembelajaran ilmu fiqih serta dijadikan acuan dalam melihat kemampuan siswa dalam mempelajari ilmu fiqih.

Kata Kunci: Mobile learning, Algoritma Fisher Yates, Fiqih, MySQL, RUP, UML

The conventional learning process carried out face-to-face, is less effective as a source of learning, because the focus of students' interest has now shifted to their device so that students have difficulty repeating learning material. This study aims to produce learning media based on mobile learning on the android platform which is used as a source of learning fiqh applications for students. This mobile learning application is built by applying the Fisher Yates Shuffling algorithm or commonly known as the Fisher Yates algorithm which is now widely used in the process of developing randomization applications. This randomization method is the optimal randomization method in application development, being able to randomize the amount of material about the science of jurisprudence and prevent cheating users who only memorize answers without understanding the material when the questions are fixed or not random. Applications are built using MySQL as a database designed to manage and manipulate data quickly and easily. PHP and Perl are used as scripting programming languages for the internet and collaborate on the Android platform. The system development method used is RUP (Rational Unified Process) by collecting various best practices found in the software development industry. System testing is done using a white box and black box testing shows that the Fisher Yates algorithm can be applied in the mobile learning quiz application as a randomizer about questions. User Acceptance Model (UAT) test results show that this mobile learning application can help the process of learning the science of jurisprudence as well as being a reference in seeing the ability of students to learn the science of jurisprudence.

Keywords: Mobile learning, Fisher Yates Algorithm, Fiqih, MySQL, RUP, UML 
JURNAL NUANSA INFORMATIKA

Volume 13 Nomor 2, Juli 2019

\section{PENDAHULUAN}

Fiqih adalah ilmu yang berisi tentang hukum yang mengatur hubungan manusia dengan Tuhannya. Ilmu fiqih juga merupakan bagian dari syari'at yang wajib dipelajari oleh setiap muslim. Pengamatan yang dilakukan dalam proses pembelajaran secara konvensional dengan tatap muka, dimana pembelajaran hanya dilakukan melalui media buku, masih ditemukan sebagian besar siswa yang kurang memahami tentang ilmu fiqih tersebut. Sementara dari sisi peserta didik, fokus ketertarikan mereka lebih senang menggunakan perangkat gawai daripada membaca buku. Ketertarikan siswa terhadap perangkat gawai hampir dalam kehidupan sehari-hari, memberikan peluang positif sebagai alternatif media pembelajaran.

Penelitian [1] mengembangkan kuis multimedia interaktif sebagai media pembelajaran model drill and practice untuk meningkatkan hasil belajar siswa. penelitian tersebut menunjukan hasil yaitu hampir seluruh siswa memberikan respon positif mengenai pembelajaran yang menggunakan multimedia pembelajaran model drill and practice dengan game kuis interaktif, siswa memberikan penilaian sangat baik terhadap multimedia pembelajaran game kuis interaktif dengan persentase penilaian sebesar $91.979 \%$, dan mengalami peningkatan hasil belajar.

Mekanisme utama dalam kuis adalah pengacakan soal,maka pada penelitian [2], membuat sebuah sistem yang dapat digunakan untuk latihan mengerjakan soal ujian nasional berbasis ponsel android dengan menerapkan algoritma Fisher-Yates Shuffle untuk pengacakan soal agar soal dalam kuis mempunyai urutan yang berbeda. Berdasarkan presentase kepuasan kinerja dan manfaat yaitu $88,74 \%$, Sistem kuis latihan soal mengerjakan ujian nasional di nilai dapat di gunakan sebagai latihan untuk menghadapi ujian nasional. Selain itu, setelah dilakukan pengujian black box algoritma Fisher-Yates Shuffle berhasil diterapkan pada sistem kuis latihan soal mengerjakan ujian nasional berbasis
p-ISSN : 1858-3911, e-ISSN : 2614-5405

https://journal.uniku.ac.id/index.php/ilkom

android.

Penelitian ini bertujuan untuk membangun media pembelajaran berbasis mobile learning pada platform android yang digunakan sebagai sumber belajar aplikasi fiqih pada anak didik dengan menerapkan algoritma Fisher-Yates Shuffle algoritma Fisher-Yates Shuffle untuk pengacakan soal. Pengembangan sistem dilakukan menggunakan metode RUP dimana tahap analisis, dilakukan pengacakan pada database soal fiqih yang akan diujikan dalam kuis. Keluaran dari analisis pengacakan ini adalah soal yang sudah teracak dan ditampilkan dalam aplikasi kuis

\section{METODOLOGI PENELITIAN}

Penelitian dilakukan melalui tahapan beberapa metode. Metode pengumpulan data dilakukan dengan wawancara dengan guru dan peserta didik, obsrvasi secara langsung pada sekolah-sekolah dan studi pustaka dengan terkait penelitian sebelumnya dalam jurnal dan prosiding seminar. Metode pemecahan masalah melalui implementasi algoritma Fisher Yates Shuffle yang digunakan dalam mengacak soal-soal kuis fiqih. Sementara pengembangan sistem mengunakan Rational Unified Process (RUP).

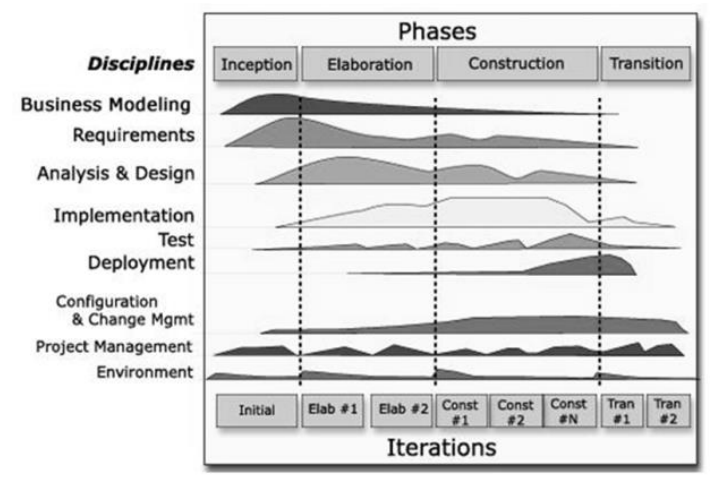

Gambar 1. Metode RUP [3]

\subsection{Perancangan Sistem Usulan}

Aplikasi Mobile Learning Kuis Fiqih merupakan sebuah sistem pembelajaran berupa kuis materi fiqih berbasis aplikasi bergerak, sebagaimana berikut: 
JURNAL NUANSA INFORMATIKA

Volume 13 Nomor 2, Juli 2019

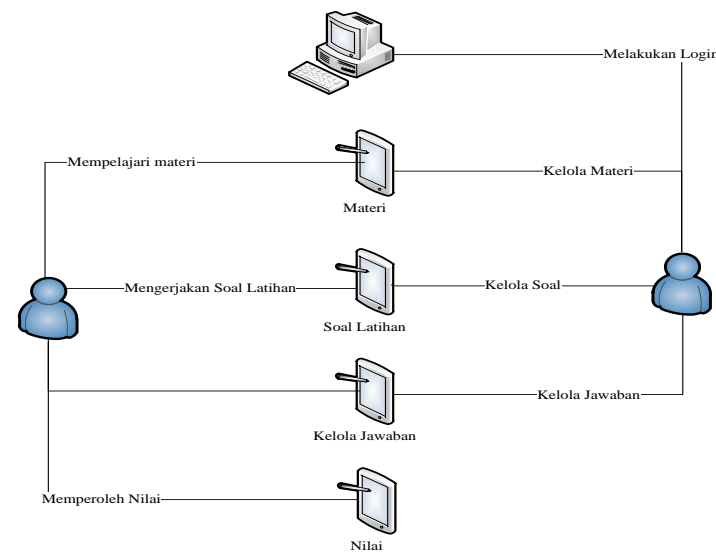

Gambar 2. Gambaran Sistem Usulan

\subsection{Pengembangan Sistem}

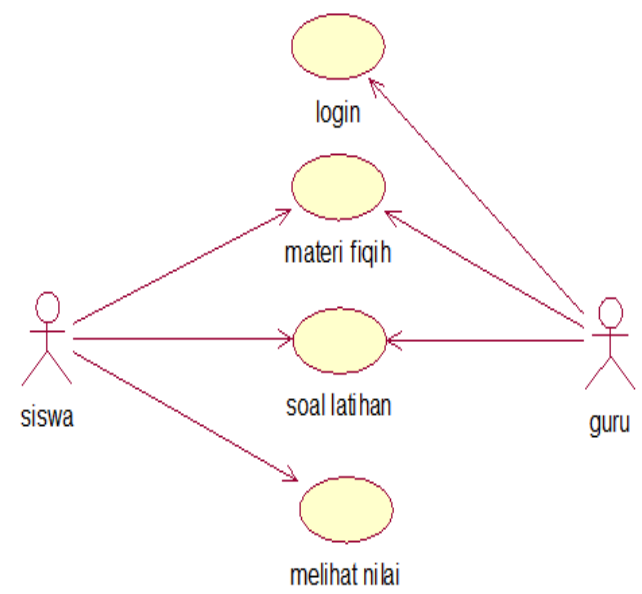

Gambar 3. Use Case Sistem Usulan

Sistem yang diusulkan berupa interaksi kuis pembelajaran yang dapat diakses oleh siswa kapanpun dan dimanapun. Secara sistem, siswa akan mengakses aplikasi, melakukan permainan kuis dan melihat nilai. Sementara guru berinteraksi dengan aplikasi saat mengunggah soal-soal kedalam database soal.

\subsection{Penyelesaian Masalah Pengacakan Soal}

Pengacakan soal menjadi faktor penting dalam kuis fiqih berbasis aplikasi bergerak ini. Metode yang digunakan untuk penyelesaian masalah yaitu menggunakan algoritma Fisher Yates sebagaimana berikut:
p-ISSN : 1858-3911, e-ISSN : 2614-5405

https://journal.uniku.ac.id/index.php/ilkom

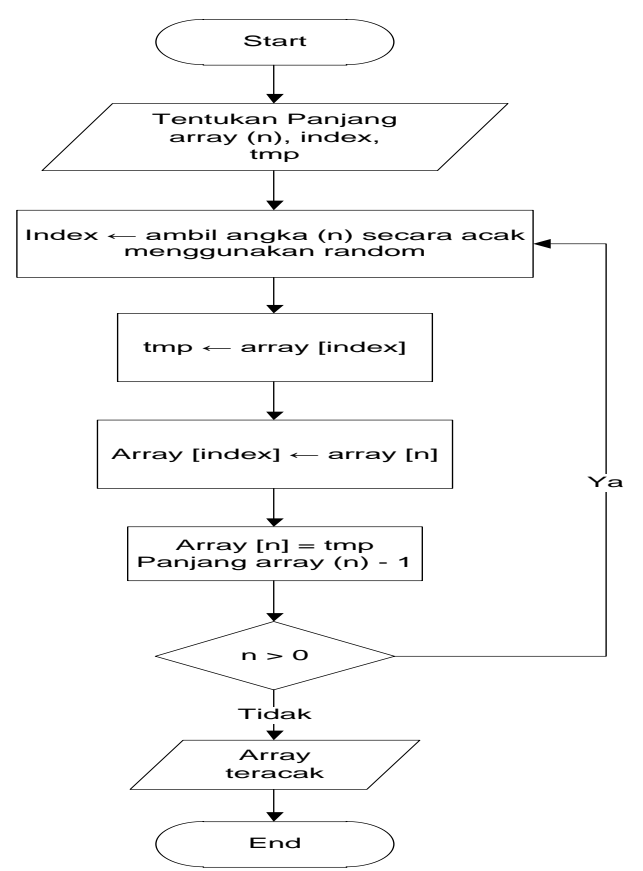

Gambar 3. Flowchart Diagram Alir Algoritma Fisher Yates [4]

Penerapan algoritma Fisher Yates dalam pengacakan soal, dapat dilihat dalam tabel dibawah ini:

\begin{tabular}{|l|l|l|l|}
\hline Range & Roll & \multicolumn{1}{|c|}{ Scratch } & Result \\
\hline & & 12345678 & \\
\hline $1-8$ & 5 & 1234867 & 5 \\
\hline $1-7$ & 3 & 127486 & 35 \\
\hline $1-6$ & 8 & 12746 & 835 \\
\hline $1-5$ & 2 & 1674 & 2835 \\
\hline $1-4$ & 1 & 467 & 12835 \\
\hline $1-3$ & 6 & 47 & 612835 \\
\hline $1-2$ & 4 & 7 & 4612835 \\
\hline \multicolumn{3}{|c|}{ Hasil Pengacakan : } & $\mathbf{7 4 6 1 2 8 3 5}$ \\
\hline
\end{tabular}

Tabel 1. Proses Pengacakan Algoritma Fisher Yates

\section{HASIL DAN PEMBAHASAN}

\subsection{Implementasi Sistem}

Spesifikasi perangkat lunak pengembang untuk implementasi algoritma Fisher Yates aplikasi mobile learning kuis fiqih berbasis android, meliputi: Xampp v1.7.7 sebagai web server yang didalamnya disertai PHPmyadmin sebagai database; OS 
JURNAL NUANSA INFORMATIKA

Volume 13 Nomor 2, Juli 2019

menggunakan Windows 7. Perangkat lunak penggguna minimum dengan OS Android minimal 4.0 Ice Cream Sandwich (ICS); Browser menggunakan Mozilla Firefox. Sementara dari sisi perangkat keras pengguna, minimum spesifikasi minimum, meliputi: Processor minimum Single core $300 \mathrm{MHz}$; RAM minimum $256 \mathrm{Mb}$; Memori Internal 4 GB.

\subsection{Implementasi Algoritma Fisher Yates}

Input dari proses pengacakan dengan algoritma Fisher Yates adalah dengan mengambil data berupa angka atau karakter sebanyak 1-N, ambil sebuah data acak $\mathrm{k}$ di antara $1-\mathrm{N}$, coret data $\mathrm{k}$ yang belum dicoret dan tuliskan data tersebut di lain tempat, ulangi langkah hingga semua data telah di coret sehingga menghasilkan data permutasi yang baru.

Contoh hasil hasil uji coba dalam melakukan pengacakan sebanyak 3 kali di dapat permutasi acak yang berbeda, sebagai berikut:

Output Fisher Yates 1

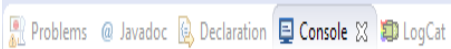

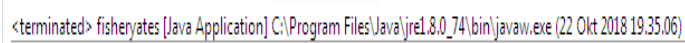
309182322210617122014288161925153547292621132411127

Output Fisher Yates 2

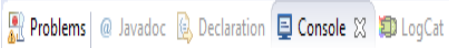

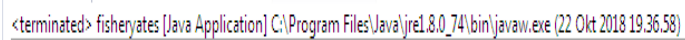
208252952122281311141224173302667169151219231041827

Output Fisher Yates 3

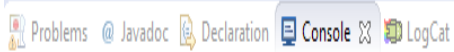

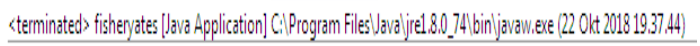
110182114712173028202725292224511323162151961382649

\subsection{Implementasi Antarmuka}

Antarmuka yang akan digunakan oleh pengguna dalam hal ini Guru dan Siswa, disajikan dalam menu dan navigasi halaman sebagaimana berikut dibawah ini:
p-ISSN : 1858-3911, e-ISSN : 2614-5405

https://journal.uniku.ac.id/index.php/ilkom

a. Halaman Utama Siswa

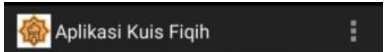

b. Halam Menu Materi

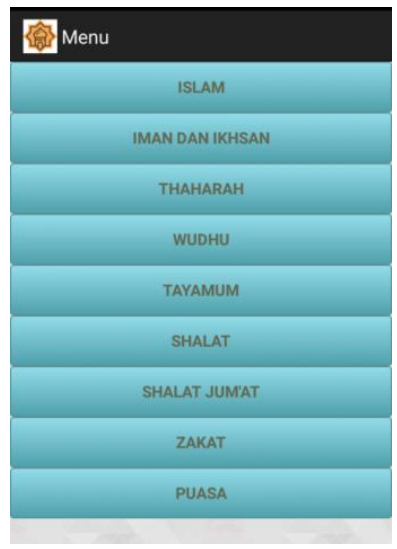

$\rightarrow$ Materi Fiqih

\section{得ISLAM}

1. ISLAM

Islam yaitu engkau mengakui bahwa tiada Tuhan selain Allah. Dan Muhammad adalah utusan Allah
mendirikan shalat, memberikan zakat mendirikan shalat, memberikan zakat, berpuasa
dibulan Ramadhan dan beribadah haji ke Baitullah engkau sanggup melakukan perjalanan kesana. (H.R Muslim).

Apa yang Rasulullah SAW sabdakan tersebut kita kena dengan rukun Islam. Kita baru bisa disebut muslim yang sempurna jika
Islam tersebut, yaitu.

A. Mengucapkan dua kalimat syahada

B. Mendirikan shalat lima wak

C. Membayar Zakat

E. Beribadah haji ke Baitullah bagi orang yang mampu 
JURNAL NUANSA INFORMATIKA

Volume 13 Nomor 2, Juli 2019

c. Halaman Menu Soal

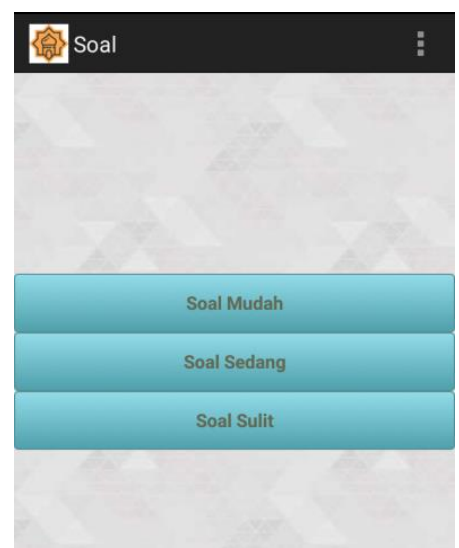

Menu Soal Yang Dipilih

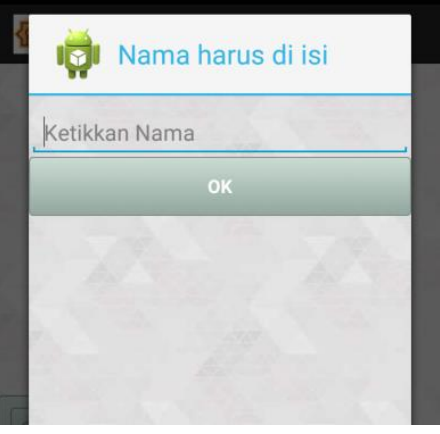

$\rightarrow$ Tampilan Soal Yang Harus Dikerjakan

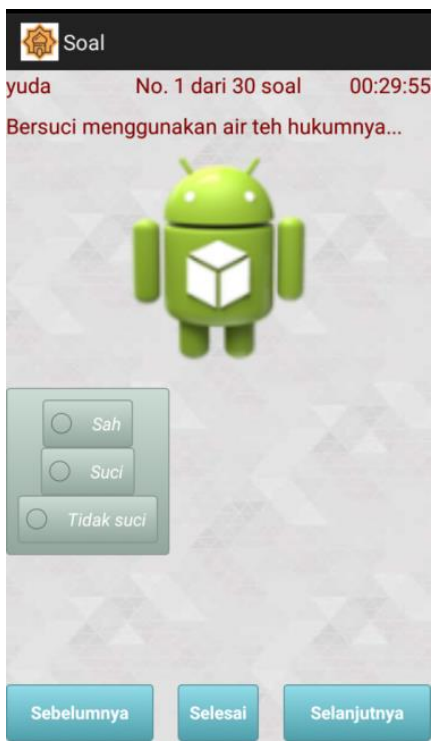

Tampilan Skor
p-ISSN : 1858-3911, e-ISSN : 2614-5405

https://journal.uniku.ac.id/index.php/ilkom

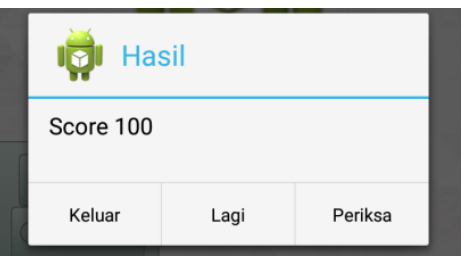

$\rightarrow$ Halaman Periksa Jawaban

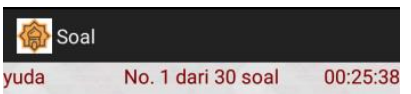

Bersuci menggunakan air teh hukumnya..

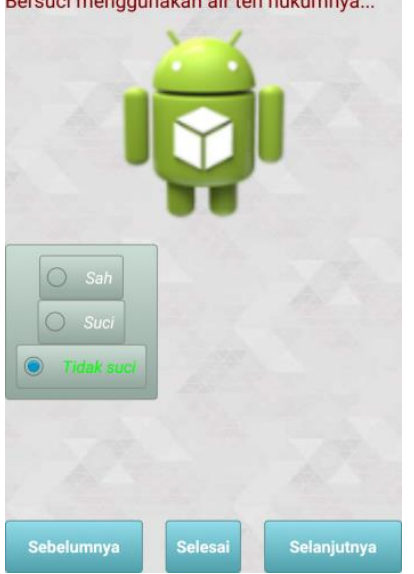

d. Halaman Bantuan

\section{堬Bantuan}

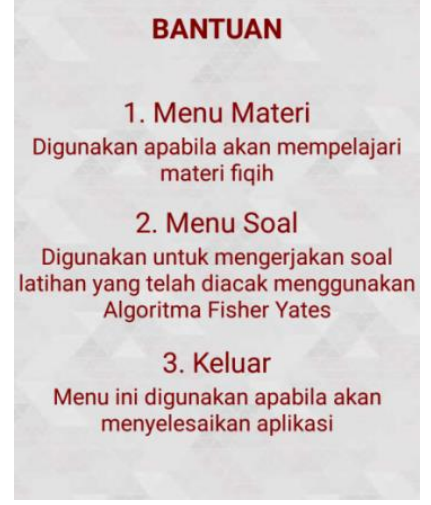

\section{e. Halaman Menu Keluar}

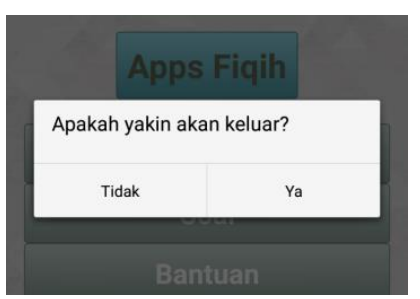

\section{f. Halam Login Guru}


JURNAL NUANSA INFORMATIKA

Volume 13 Nomor 2, Juli 2019

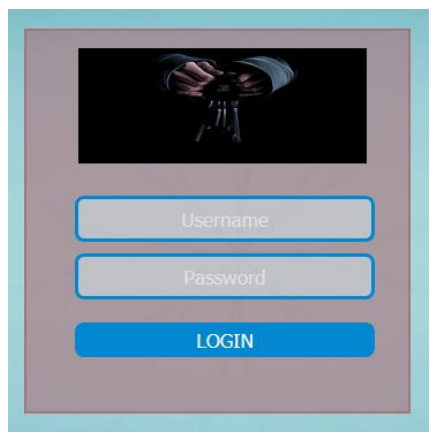

g. Halaman Utama Guru

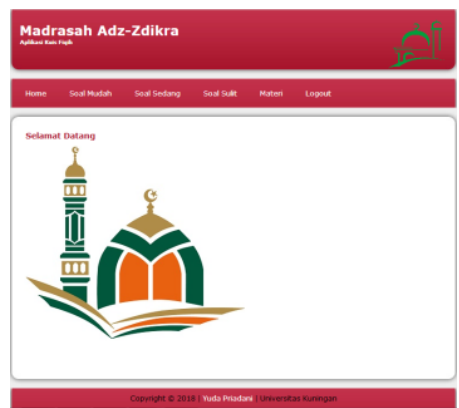

h. Halaman Data Soal

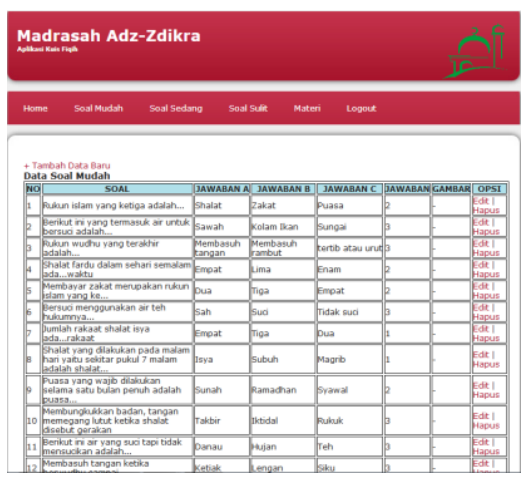

i. Halaman Input Data Soal

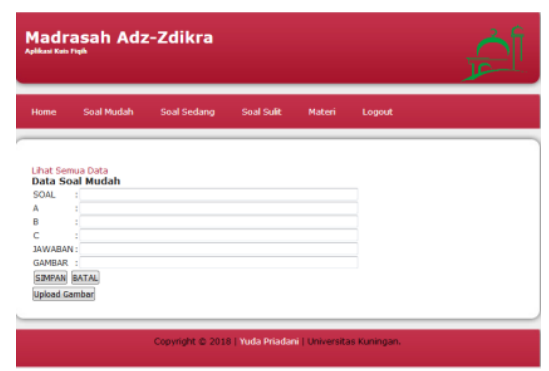

\subsection{Pengujian Sistem}

a. Pengujian Black Box dan White Box

Black Box Testing memberikan hasil bahwa semua fungsi Aplikasi
p-ISSN : 1858-3911, e-ISSN : 2614-5405

https://journal.uniku.ac.id/index.php/ilkom

Mobile Learning Kuis Fiqih telah berjalan semestinya sesuai dengan kebutuhan fungsional yang telah didefinisikan.

White Box Testing memberikan hasil bahwa struktur kontrol program dari beberapa sampel keode program mampu melalui Flowgraph Complexity Cyclomatic

b. Pengujian User Acceptance Test (UAT)

Siswa memberikan penilaian

Sangat Baik terhadap Aplikasi Mobile Learning Kuis Fiqih dengan persentase penilaian sebesar 90.79\% dalam peningkatan belajar. Sementara dari sisi Guru, memeberikan penilaian yang Baik pada presentase $87.56 \%$ dalam kemudahan memberikan pelajaran.

\section{KESIMPULAN}

Kesimpulan yang diperoleh dari penelitian implementasi algoritma fisher yates untuk pengacakan soal pada aplikasi mobile learning kuis fiqih berbasis android ini adalah sebagai berikut :

a. Pengacakan menggunakan algoritma Fisher Yates dapat diterapkan di dalam aplikasi mobile learning kuis fiqih sebagai pengacak soal yang akan muncul dalam setiap keluarnya soal tidak berulang.

b. Aplikasi mobile learning kuis fiqih dapat membantu proses pembelajaran ilmu fiqih

c. Aplikasi mobile learning kuis fiqih dapat dijadikan acuan dalam melihat kemampuan siswa dalam mempelajari ilmu fiqih

\section{SARAN}

Penelelitian masih memiliki kekurangan, maka dalam rangka pengembangan aplikasi mobile learning kuis fiqih ini:

a. Aplikasi mobile learning kuis fiqih ini diharapkan dapat dikembangkan 
JURNAL NUANSA INFORMATIKA

Volume 13 Nomor 2, Juli 2019

dengan lebih baik lagi mengenai interface, maupun yang lainnya.

b. Membandingkan algoritma Fisher Yates dengan algoritma lainnya sebagai evaluasi
p-ISSN : 1858-3911, e-ISSN : 2614-5405

https://journal.uniku.ac.id/index.php/ilkom

\section{DAFTAR PUSTAKA}

[1] Miftah Farid Adiwisastra, " PERANCANGAN GAME KUIS INTERAKTIF SEBAGAI MULTIMEDIA PEMBELAJARAN DRILL AND PRACTICE UNTUK MENINGKATKAN HASIL BELAJAR SISWA," AMIK BSI Tasikmalaya, 2015.

[2] Agusman Riyadi, Etika Kartikadarma, " PENERAPAN ALGORITMA FISHERYATES SHUFFLE PADA SISTEM KUIS UNTUK LATIHAN MENGERJAKAN UJIAN NASIONAL BERBASIS ANDROID ", Universitas Dian Nuswantoro.

[3] Taryana Suryana,"Metode RUP", 2007.

[4] Rio Andriyat Krisdiawan, Tri Ramdhany, "Implementasi Algoritma Fisher Yates Pada Games Edukasi Pengenalan Hewan Untuk Anak SD Berbasis Mobile Android", 2018 